NBER WORKING PAPER SERIES

\title{
MANAGING CONTRIBUTION AND CAPITAL MARKET RISK IN A FUNDED PUBLIC DEFINED BENEFIT PLAN:
} IMPACT OF CVAR COST CONSTRAINTS

\author{
Raimond Maurer \\ Olivia S. Mitchell \\ Ralph Rogalla \\ Working Paper 14332 \\ http://www.nber.org/papers/w14332 \\ NATIONAL BUREAU OF ECONOMIC RESEARCH \\ 1050 Massachusetts Avenue \\ Cambridge, MA 02138 \\ September 2008
}

This research was conducted with support from the TransCoop Program of the Alexander von Humboldt Foundation and the Pension Research Council (PRC) at The Wharton School of the University of Pennsylvania. We are grateful for useful comments from Peter Brady, Peter König, and Steven Haberman, and for data provided by the Hessian Statistical Office. This is part of the NBER Program on the Economics of Aging. Opinions and errors are solely those of the authors and not of the institutions with whom the authors are affiliated nor the National Bureau of Economic Research.

NBER working papers are circulated for discussion and comment purposes. They have not been peerreviewed or been subject to the review by the NBER Board of Directors that accompanies official NBER publications.

(C) 2008 by Raimond Maurer, Olivia S. Mitchell, and Ralph Rogalla. All rights reserved. Short sections of text, not to exceed two paragraphs, may be quoted without explicit permission provided that full credit, including $\odot$ notice, is given to the source. 
Managing Contribution and Capital Market Risk in a Funded Public Defined Benefit Plan:

Impact of CVaR Cost Constraints

Raimond Maurer, Olivia S. Mitchell, and Ralph Rogalla

NBER Working Paper No. 14332

September 2008

JEL No. G11,G15,G2,G23,H3,H55,H71,J26,J32

\begin{abstract}
Using a Monte Carlo framework, we analyze the risks and rewards of moving from an unfunded defined benefit pension system to a funded plan for German civil servants, allowing for alternative strategic contribution and investment patterns. In the process we integrate a Conditional Value at Risk (CVaR) restriction on overall plan costs into the pension manager's objective of controlling contribution rate volatility. After estimating the contribution rate that would fully fund future benefit promises for current and prospective employees, we identify the optimal contribution and investment strategy that minimizes contribution rate volatility while restricting worst-case plan costs. Finally, we analyze the time path of expected and worst-case contribution rates to assess the chances of reduced contribution rates for current and future generations. Our results show that moving toward a funded public pension system can be beneficial for both civil servants and taxpayers.
\end{abstract}

Raimond Maurer

Finance Department, Goethe University

House of Finance (Uni-PF H 23)

Grüneburgplatz 1

D-60323 Frankfurt am Main, Germany

rmaurer@wiwi.uni-frankfurt.de

Olivia S. Mitchell

Dept of Insurance \& Risk Management

University of Pennsylvania, Wharton School

3620 Locust Walk, St 3000 SH-DH

Philadelphia, PA 19104-6302

and NBER

MITCHELO@WHARTON.UPENN.EDU
Ralph Rogalla

Goethe University of Frankfurt

House of Finance (Uni-PF H 23), Gr

D-60323 Frankfurt am Main

rogalla@wiwi.uni-frankfurt.de 


\section{Managing Contribution and Capital Market Risk in a Funded Public Defined Benefit Plan: Impact of CVaR Cost Constraints}

\section{Introduction}

Traditional PAYGO public pension plans confront demographic aging in most developed nations, and some policymakers advocate boosting funding to ease the crunch of paying for the future pension liability. In the case of civil servant pensions, a handful of these have substantial assets including in the Netherlands (ABP 2006) and the state of California (Mitchell et al. 2001). But more generally, and in Germany in particular, civil servants are often promised a non-contributory, tax-sponsored defined benefit (DB) pension which is usually not funded. This study evaluates the impact of an alternative approach to public sector pension fund management, by deriving optimal contribution rate and asset allocation patterns in a partially funded scheme for the German federal state of Hesse. We show this approach can be useful in permitting a state to finance its public pensions so as to cut costs for taxpayers and enhance pension security for participants.

Plan sponsors are generally concerned with two types of risk, namely contribution rate and solvency risk (Lee 1986; Haberman, Butt, and Megaloudi 2000). When managing the funded pension, plan sponsors and beneficiaries wish to insure that plan funds will be sufficient to cover pension liabilities, while ideally smoothing contribution rates over time. To combine both types of risk, traditional studies on managing DB pensions have introduced a quadratic cost criterion as the plan manager's objective function (c.f. Haberman and Sung 1994, 2005; Haberman 1997a,b; Ngwira and Gerrard 2007; and Owadally and Haberman 2004). These risks are typically measured by squared deviations of current contribution rates and funding levels from their expected or notional values. ${ }^{1}$ Another approach adopts a Conditional Value at Risk (CVaR) criterion as a key risk measure used for plan control: the

\footnotetext{
${ }^{1}$ Other plan manager objectives could include expected utility from dividends paid by the pension plan or from possible terminal surplus values (c.f. Hainaut and Devolder 2007; Detemple and Rindisbacher 2008).
} 
CVaR of a parameter at the $\alpha$ percent confidence level is defined as the parameter's expectation under the condition that its realization exceeds the Value at Risk (VaR) for that level (Artzner et al. 1997, 1999; Rockafellar and Uryasev 2002). For instance, Bogentoft, Romeijn, and Uryasev (2001) include CVaR constraints on funding levels while seeking to minimize total costs of pension funding. Maurer, Mitchell, and Rogalla (2008a, b) directly minimize the Conditional Value at Risk of total pension costs, while Haberman et al. (2003a, b) investigate the trade-off between mean shortfall risk (i.e. CVaR on plan solvency) and excess contribution rate risk.

In this paper, we identify contribution and investment strategies that minimize pension contribution rate risk (as in Haberman, Butt, and Megaloudi 2000), and we also impose $\mathrm{CVaR}$ restrictions on total plan costs appropriate to a public pension scheme. ${ }^{2}$ Focusing on the $\mathrm{CVaR}$ of the stochastic present value of plan costs offers an elegant and objective way to compare different intertemporal contribution and investment paths on a common basis. Moreover, this approach allows us to explicitly incorporate decisionmakers' risk budget, by defining the maximum admissible CVaR of plan costs.

We implement our approach in the context of German civil service pension plans. To date, only two German states have started funding a portion of their public pension liability, depositing 20-40 percent of covered payroll to the active civil servants' pension fund; these investments have been mainly restricted to government bonds. To illustrate the power of our model, we examine the Hessian public pension plan which we argue is rather representative of the public sector environment in Germany. We show that controlling only on costs requires a high regular contribution rate of about 40 percent of covered payroll. Conversely, focusing only on contribution rate volatility yields low regular contribution rates and low-risk

\footnotetext{
${ }^{2}$ In accordance with Feldstein and Ranguelova (2001) and others, we suggest that the decision to start prefunding an initially unfunded public pension plan requires attention to the cost risks associated with funding and investing in capital markets. Such a strategy may be considered only if these risks can be held to acceptable levels. Accordingly, we incorporate a restriction on the maximum size of plan costs in worst-case scenarios.
} 
asset allocations, but taxpayers are exposed to substantial risk of extraordinary but predictable transfers to cover shortfalls. Combining both approaches can produce moderate contribution rates accompanied and a substantial equity portfolio which generates acceptable contribution rate volatility while keeping total pension costs under control.

In what follows, we briefly describe the public pension on which we focus, and we derive the value of plan liabilities and payroll-related contribution rates needed to finance them. Section 3 outlines the plan manager's objective function and the model underlying the asset/liability management process. Results of our stochastic simulation study are detailed in Section 4. A final Section concludes.

\section{Valuing Public Pension Liabilities in a Non-Stochastic Framework: The German}

\section{Civil Servant Plan}

German civil servants have traditionally been promised a noncontributory, taxsponsored, unfunded, and relatively generous DB-type annuity that depends on retirement age, years in civil service, and final salary. ${ }^{3}$ In exchange for this plan, civil servants do not participate in the national social security system nor are they covered by supplementary occupational pensions (Heubeck and Rürup 2000). Over time, civil servant pensions have become less generous: the retirement age, which had been 65 , is being raised to 67 , and pension accruals have been reduced to approximately 1.79 percent of final salary per service year. This will generate a maximum replacement rate of 71.75 percent after 40 years of service (versus 75 percent under the old rules).

\subsection{Civil Service Employee Dataset}

We base our assessment of the public plan by focusing on civil servants employed by the German federal state of Hesse. This population of civil servants is rather representative of

\footnotetext{
${ }^{3}$ For a more detailed discussion of the German civil servant pension system and the dataset employed in this study, see Maurer, Mitchell, and Rogalla (2008a, b).
} 
the approximately 1.5 million active (about $4.5 \%$ of the workforce) and 900,000 retired civil servants in Germany as a whole. ${ }^{4}$ The dataset provided by the Hessian Statistical Office includes anonymized files on active civil servants in 2004 in Hesse reporting their age, sex, marital status, line of service, and salary. ${ }^{5}$ There are 104,919 active civil servants in the database: the average age is 44.7 years, earning an average salary of $€ 39,000$, and 45 percent female. Payroll amounted to an annual $€ 4.26$ billion or 33 percent of Hesse's annual state tax revenues in that year.

\subsection{Population Dynamics and Economic Assumptions}

This analysis of a transition toward a funded pension incorporates both current employees as well as those to be hired in the future into the calculations. (Unfunded past service liabilities are assumed to be covered from other revenue sources, as in Maurer, Mitchell, and Rogalla 2008a, b). Projecting the civil service population requires forecasting the evolution of age and salary for existing employees, as well as making assumptions about new hires. Since practically speaking, employee turnover for reasons other than retirement is insignificant, we assume that all workers remain active until age 67 and reach retirement with certainty. ${ }^{6}$ Vacant positions are assumed to be filled with new recruits with a $50 \%$ chance of being male or female. Each new worker's entry age is set to the empirical average age of new hires, accounting for average time spent in position-related education or service credited as prior creditable years. New workers receive the age-related remuneration for their positions and marital status is that of the previous position holder. Retired civil servants are represented by the expected cash flows of the indexed life annuities they receive according to the civil

\footnotetext{
4 These numbers include only federal and state civil servants, but not the approximately 200,000 active and 500,000 retired civil servants who worked for former state-owned (now privatized) enterprises such as the German national railway and federal mail (Bundesministerium des Innern, 2005).

${ }^{5}$ Information on a handful of top-level civil servants, judges, and state attorneys is omitted to preserve anonymity.

${ }^{6}$ Provisions for early retirement and disability benefits, as well as dependents' benefits due to death in service, must therefore be conducted separately from this analysis.
} 
service pension benefit formula. (For married retirees we calculate indexed joint-and-survivor annuities, assuming that both partners are of same age and opposite sex.)

To value the civil servant pension liability profiles, we use mortality tables specific to the Hessian civil service derived by Maurer, Mitchell, and Rogalla (2008a). Future mortality improvements are incorporated using an exponential trend function suggested by the German Association of Actuaries ('Zieltrend 2. Ordnung'; c.f. DAV 2004, p. 56ff.). Employing this trend function, by 2030 the mortality of a female civil servant aged 65 will fall by 40 percent. Inflation, salary growth, and investment returns have significant influence on pension plan valuation and must also be considered in forecasting future benefit accruals (Hustead and Mitchell 2001). The analysis is conducted in real terms, inasmuch as salaries and pension benefits tend to be tied to the consumer price index; accordingly, the growth rate of real wages and real pensions is zero. Because pension liabilities have a long duration, they are highly sensitive to the discount rate selected. Our analysis adopts the economic approach to pension valuation so we capitalize liabilities at the real rate on (quasi-) risk-free long-term government bonds reflecting the state's financing costs. ${ }^{7}$ We set the real risk-free interest rate at 3 percent in our base case, a more conservative assumption than the nominal 8 percent employed by US state-sponsored pension plans (Novy-Marx and Rauh 2008). ${ }^{8}$ To check the interest rate sensitivity of our findings, we also report results using a 1.5 percent a real interest rate.

\footnotetext{
${ }^{7}$ For a detailed discussion on the differences between the economic and the actuarial approach to pension valuation, see Blake (2006, p. 77).

${ }^{8}$ Adjusting average nominal par yields of long-term German government bonds by the average inflation rate for the post-WWII period results in real returns of about 4 percent. The yield on European inflation indexed bonds is currently about 2 percent. However, the markets for indexed long duration government bonds are still not well developed, so we base our analyses on the assumption of a real discount rate of 3 percent. Moreover, the federal state of Saxony uses a nominal discount rate of 4.75 percent for valuing their pension liabilities. Accounting for a long-run inflation target of $2 \%$ set by the European Central Bank, this lies in range of our real 3 percent base case discount rate.
} 


\subsection{Deriving Future Contribution Rates}

If plan sponsors seek to fund their pension scheme, they must analyze pension liability patterns so as to derive the contribution rate adequate to pay for plan liabilities. To determine the plan's normal cost, we employ the aggregate level percentage of payroll method which expresses total projected plan costs as a percentage of active members' payroll (McGill et al. 2005). Starting with the initial civil service population and developing it over the next 50 years, we calculate the present values of future salary payments as well as future pension payments and accruals. We conduct a discontinuance valuation as of the last period (2053), computing the projected benefit obligation (PBO) for all outstanding pension promises. ${ }^{9}$ The ratio of the present values of pension liabilities and salary payments represents the deterministic yearly contribution rate required to fund pension promises, expressed as a percentage of active civil servants' payroll. ${ }^{10}$

In the base case with a 3 percent discount rate, the present value of future pension liabilities amounts to $€ 20.8$ billion versus the present value of salary payments of $€ 111.5$ billion. Therefore, the smoothed average contribution rate required to pay for the pension promises is 18.7 percent of salaries. Applying an alternative discount rate of 1.5 percent increases the present value of pension liabilities to $€ 44.8$ billion and that of salary payments to $€ 149.3$ billion. Since pension liabilities exhibit longer duration than salary payments, decreasing discount rates will increase contribution rates - in this case, from 18.7 to 30 percent.

\footnotetext{
${ }^{9}$ While this horizon could easily be further extended beyond 50 years, all the then-active civil servants will be fully covered by the funded system and all retirees will receive a significant fraction of their benefits from the funded system.

${ }^{10}$ Throughout, we set aside the past service pension obligation accrued by current and past workers on the presumption that these will have to be handled with some other financing mechanism.
} 


\section{Stochastic Investment Returns and Pension Plan Funding}

\subsection{The Pension Manager's Objectives and Asset/Liability Management}

When investment returns are stochastic, the plan manager is posited to minimize the variability of annual plan contributions, while at the same time ensuring that (worst-case) plan costs are kept under control. To this end, the manager is free to choose a fixed rate of normal contributions $C R$ as a fraction of salaries, as well as a constant allocation of plan assets to equities and bonds. ${ }^{11}$ We assume that at the beginning of each period $t$, the sponsor endows the plan with regular contributions $R C_{t}$ based on $C R$ and salary payments in $t$. These funds are then used to pay for pensions due at time $t$, and any remaining plan assets are invested. At the end of every period, the plan's funding situation is scrutinized by comparing current plan liabilities measured by the $\mathrm{PBO}_{t+1}$ and current plan assets $A_{t+1}$. If plan liabilities exceed plan funds, additional contributions will be required to re-establish the balance between assets and liabilities. On the other hand, if assets exceed liabilities, this will permit lower contributions to the plan.

Funding deviations are reduced by amortizing the shortfall over a period ranging from 1 to 20 years, depending on the manager's control function. In other words, we employ the spread method described by Haberman (1997a) to determine how much additional beyond normal costs must be added to cover underfunding. The plan's liability at the end of period $t$, i.e. $P B O_{t+1}$, is calculated as:

$$
P B O_{t+1}=\sum_{i} \frac{1.79375 \% \cdot \tau_{i, t+1} \cdot S_{67, i} \cdot \bar{a}_{67, i}}{(1+r)^{67-\text { Age }_{i, t+1}}}
$$

where (for each civil servant $i$ of $A g e_{i, t+1}$ ) $\tau_{i, t+1}$ is the number of pensionable service years accrued until $t+1, S_{67, i}$ is the projected salary at retirement age $67, \bar{a}_{67, i}$ is the immediate pen-

\footnotetext{
${ }^{11}$ Here, we follow Haberman et al. (2003a, p. 513) who show that pension funds tend to exhibit rather stable asset allocations over time.
} 
sion annuity factor at age $67, r$ is the discount rate, and $1.79 \%$ is the final salary-related replacement rate per pensionable service year.

We define $U L_{t+1}=P B O_{t+1}-A_{t+1}$ as the unfunded liability at the end of period $t$ (at the beginning of period $t+1$ ), which is to be recovered over a pre-specified time horizon $m$, the spread period. ${ }^{12}$ Then, the total contribution to the plan in $t+1\left(C_{t+1}\right)$ is the sum of regular contributions $\left(R C_{t+1}\right)$ and adjustment payments $A D J_{t+1}$ :

$$
C_{t+1}=R C_{t+1}+A D J_{t+1}
$$

with

$$
A D J_{t+1}=A N F_{m, r} \cdot U L_{t+1},
$$

where $A N F_{m, r}$ is the annuity factor for an $m$-period time annuity due calculated at the discount rate $r$ according to

$$
A N F_{m, r}=\left(\sum_{i=0}^{m-1} \frac{1}{(1+r)^{i}}\right)^{-1}
$$

For simplicity, the amortization or spread period $m$ is assumed to be the same for asset shortfalls as well as surpluses (which in practice, may not always be true; c.f. Winklevoss 1993).

Finally, we stipulate that the overall contributions $C_{t+1}$ may not be negative, i.e. that $R C_{t+1} \geq-A D J_{t+1}$. Thus negative adjustment payments are limited in each period to the current regular contributions; the manager is prohibited from withdrawing from the pension fund for other purposes. The rationale for this is that political decisionmakers are sometimes tempted to withdraw funds and misuse them for short-term political objectives when plans are overfunded. We seek to avoid this by imposing structural withdrawal restrictions.

To derive the optimal investment and contribution policy for this public pension plan, we run a Monte Carlo simulation with 10,000 iterations. The optimal policy parameters for the pension plan - the normal contribution rate $C R$ and the equity weight $x$ - are computed

\footnotetext{
${ }^{12}$ For a discussion of optimal spread period lengths see Dufresne (1988), Haberman (1997a), and Owadally and Haberman $(1999,2004)$.
} 
assuming that the plan sponsor's objective is to minimize the variance of periodic contributions around the normal contribution rate over time, under the constraint that the Conditional Value at Risk $(\mathrm{CVaR})$ at the 1 percent level of the stochastic present value of total pension costs $T P C$ does not exceed a pre-specified level $c$. This integrates the approaches by Haberman, Butt, and Megaloudi (2000), ${ }^{13}$ who use a combined measure of contribution and funding volatility as objective function, and Maurer, Mitchell, and Rogalla (2008a, b), who seek to minimize the $C V a R$ of total pension costs.

More formally, the plan manager's optimization problem can be defined as follows:

$$
\begin{aligned}
& \min _{C R, x} E\left[\sum_{t=1}^{T-1}\left(\frac{C_{t}}{\text { Salary Payments }}-C R\right)^{2}\right] \\
& \text { s.t. } \\
& C \operatorname{VaR}_{1 \%}(T P C) \leq c,
\end{aligned}
$$

where the constant $c$ describes the tolerable level of worst-case pension costs, which we will assume is determined by the deterministic pension liability derived in section 2.3 (i.e. $€ 20.8$ billion in case of a discount rate of $3 \%$ ).

Following Maurer, Mitchell, and Rogalla (2008a, b), the stochastic present value of total pension costs $T P C$ is calculated according to:

$$
T P C=\sum_{t=1}^{T} \frac{R C_{t}+S C_{t}\left(1+\xi_{1}\right)-W_{t}\left(1-\xi_{2}\right)}{(1+r)^{t}},
$$

where $R C_{t}$ denotes regular contributions in $t$ based on the fixed normal contribution rate $C R$ and the payroll in $t$ and supplementary contributions $S C_{t}$ and withdrawals $W_{t}$ are defined as:

$$
S C_{t}=\left\{\begin{array}{c}
A D J_{t} \mid A D J_{t}>0 \\
0, \text { else }
\end{array} \quad W_{t}=\left\{\begin{array}{c}
-A D J_{t} \mid A D J_{t}<0 \\
0, \text { else }
\end{array} .\right.\right.
$$

\footnotetext{
${ }^{13}$ Specifically, we use their objective function assuming that parameters $w$ and $\theta$ equal 1 .
} 
Here $r$ is the fixed real discount rate reflecting government's financing costs and $\xi_{i}$ are penalty factors on supplementary contributions and withdrawals. The $\alpha \%-C V a R$ of $T P C$ is defined by:

$$
C V a R_{\alpha \%}(T P C)=E\left(T P C \mid T C P>\operatorname{VaR}_{\alpha \%}(T P C)\right) .
$$

In the objective function (5), dividing current plan costs $C_{t}$ by salary payments results in the currently applicable overall rate of contributions to the plan (as a fraction of the current payroll). Their volatility around the normal contribution rate $C R$ specified by the plan manager can be interpreted as an 'expected' contribution rate in this setting. We find it natural to include upward deviations of the contribution rate in the volatility measure. This formula also accounts for downward deviations, since setting normal contribution targets too high could result in actual contributions always falling below target (c.f. Haberman, Butt, and Megaloudi 2000). ${ }^{14}$

Supplementary contributions and withdrawals are penalized with $\xi_{i}$ to ensure that an adequate normal contribution rate is set: that is, supplementary contributions of 1 Euro cost the plan $\left(1+\xi_{1}\right)$ Euros. Conversely withdrawing 1 Euro from the plan generates only $\left(1-\xi_{2}\right)$ Euros. We do this to offset a common perception that public funds paid into the civil servant pension plan are "free" money. ${ }^{15}$

\subsection{Stochastic Asset Model}

In order to project future asset returns on investments in equities and bonds, we rely on the first-order vector autoregressive (VAR) model widely used in the academic and practi-

\footnotetext{
${ }^{14}$ By contrast, some studies do not account for upward deviations (e.g. Haberman et al. 2003a) or put more emphasis on underfunding risk and over-contribution risk (e.g Chang, Tzeng, and Miao 2003).

${ }^{15}$ For a more detailed discussion of the rationale behind the penalty factors, see Maurer, Mitchell, and Rogalla (2008). Due to the spread method applied, it is likely that contribution volatility will be significant after the final period when the plan is terminated and the discontinuance valuation undertaken. By contrast, in an ongoing plan, existing funding deviations would be recovered over time and therefore deviations in contribution rates would be substantially lower. To prevent artificially high contribution volatility from unduly influencing decision-making, we only take into account contribution rate variations until time T-1.
} 
cioner literature (Hoevenaars, Molenaar and Steenkamp 2003; Campbell, Chan and Viceira 2003; Campbell and Viceira 2005). Let $y_{t}$ be the vector:

$$
y_{t}=\left(\begin{array}{c}
r_{m, t} \\
x_{t} \\
s_{t}
\end{array}\right)
$$

that contains the real money market $\log$ return at time $t\left(r_{m, t}\right)$, the vector $x_{t}$, which includes the excess returns of equities and bonds relative to $r_{m, t}$ (i.e. $x_{i, t}=r_{i, t}-r_{m, t}$ ), and a vector $s_{t}$ describing state variables that predict $r_{m, t}$ and $x_{t}$. As predictor variables we include the nominal 3-month interest rate $\left(r_{n o m}\right)$, the dividend-price ratio $(d p)$, and the term spread $(s p r) .{ }^{16} \mathrm{We}$ assume that the dynamics of $y_{t}$ are governed by an unrestricted VAR(1) according to

$$
y_{t+1}=a+B y_{t}+\varepsilon_{t+1}
$$

with $\varepsilon_{t+1} \sim \mathrm{N}\left(\mathbf{0}, \Sigma_{\varepsilon \varepsilon}\right)$.

We calibrate the model based on quarterly logarithmic return series starting in 1973:I and ending in 2007:I. The real money market return is defined as the difference between the nominal $\log 3$-month Euribor and the price inflation (for the time before Euribor was available we use the Fibor). For the log return on German equities and the corresponding log dividend-price ratios, we rely on DAX 30 time series data provided by DataStream. In deriving the return series for the diversified bond portfolio, we rely on the approach used by Campbell and Viceira (2002). The bond return series $r_{n, t+1}$ is constructed from 10-year constant maturity yields on German bonds according to:

$$
r_{n, t+1}=\frac{1}{4} y_{n-1, t+1}-D_{n, t}\left(y_{n-1, t+1}-y_{n, t}\right)
$$

where $y_{n, t}=\ln \left(1+Y_{n, t}\right)$ is the $n$-period maturity bond yield at time $t$. $D_{n, t}$ is the duration, which can be approximated by:

\footnotetext{
${ }^{16}$ These state variables find wide acceptance in the strategic asset allocation literature (c.f. Campbell and Shiller 1988, 1991; Fama and French 1989; Campbell, Chan and Viceira 2003; Campbell and Viceira 2005; Cochrane 2005; and Brandt and Santa-Clara 2006). For a concise survey refer to Hoevenaars et al. (2008).
} 


$$
D_{n, t}=\frac{1-\left(1+Y_{n, t}\right)^{-n}}{1-\left(1+Y_{n, t}\right)^{-1}} .
$$

Assuming a flat term structure between maturities $n-1$ an $n$, we approximate $y_{n-1, t+1}$ by $y_{n, t+1}$. Excess returns are again derived by subtracting the log money market return, $x_{b, t}=r_{n, t}-r_{m, t}$. The yield spread is computed as the difference between the log 10-year zeros yield on German government bonds and the $\log 3$-months Euribor, both provided by Deutsche Bundesbank.

We use quarterly data to calibrate the VAR due to a higher number of available observations, but we are interested in yearly asset returns as our liabilities are modelled on an annual basis. To this end, we aggregate the quarterly returns generated by the asset model and adapt parameters $a$ and $\Sigma_{\varepsilon \varepsilon}$ such that the moments of yearly asset returns generated by the model presented in Table 1 reflect those of annual returns in our historic time series. ${ }^{17,18}$ Table 1 here

\section{Public Pension Plan Control in a Stochastic Framework}

\subsection{Worst-Case Pension Costs and Contribution Rate Risk}

Next we draw on the results above to derive the optimal asset allocation and normal contribution rate for the pension plan. The base case scenario assumes a spread period $m$ for any under- or overfunding of 20 years, ${ }^{19}$ a real discount rate of 3 percent to discount future pension payments, no real salary or pension increases, and a 20 percent penalty factor for

\footnotetext{
${ }^{17}$ Our historic time series generated a mean real log return on bonds of almost 5 percent p.a. resulting in equities yielding an excess return of only 1.5 percent. In this study we calculate with an expected return of 4 percent on bonds, which we consider to be more appropriate over the long run.

${ }^{18}$ The adjusted parameter estimates for quarterly data are summarized in Table 4 in the appendix.

${ }^{19}$ Within a framework comparable to the approach taken by this paper, Haberman (1997a) finds that for a discount rate of 3 percent and depending on the level of return volatility, minimizing the volatility of contributions requires spread periods ranging from 10 to 217 periods. However, he concludes that more practical values lie in the range of 20 to 30 periods, of which we choose the former for our base case scenario.
} 
supplementary contributions $\xi_{1}$ and withdrawals $\xi_{2}$, which is equivalent to 1 percent per year for the spread period.

Figure 1 shows the Conditional Value at Risk of total pension costs at the 1 percent level for alternative normal contribution rates and asset allocations. If the normal contribution rate is set at 0 and all plan funds are invested in bonds, this results in the worst-case pension costs of $€ 28.09$ billion. Increasing the contribution rate but keeping the same investment strategy has the effect of decreasing overall pension costs. This is a consequence of the penalty $\xi_{1}$ levied on supplementary contributions. With no normal contributions, all pension payments and the amortized underfunding must be financed by supplementary contributions. Higher normal contributions that impose no additional penalty reduce the amount of more expensive supplementary payments and therefore reduce overall worst-case plan costs.

\section{Figure 1 here}

If, however, normal contributions are set too high, pension costs again rise. In this situation, the plan exhibits 'structural' overfunding: that is, excess funds are offset by reducing future contributions and even withdrawing monies, if possible. Inasmuch as withdrawals are also punished with penalty payments (factor $\xi_{2}$ ), this too increases costs and makes structural overfunding undesirable. For normal contributions of 40 percent and 0 percent equities, worst-case pension costs amount to $€ 31.96$ billion.

Independent of the normal contribution rate chosen, adding equities to the plan's portfolio will at first reduce worst-case plan costs. As fund investments become more diversified, capital market risks resulting from an undiversified pure bond investment are reduced and the likelihood and size of possible supplementary contributions decrease. This effect is reversed, however, when the fraction of equities in the plan's portfolio is set too high. The investment is no-longer well diversified and growing capital market risks again lead to rising worst-case pension costs. When fully invested in equities, worst-case plan costs amount to $€ 28.05$ billion 
for normal contributions of 0 percent, and $€ 32.08$ billion for a contribution rate of 40 percent. This is a striking result. Although pure equity investments are substantially riskier than pure bond investments, worst-case pension costs in both cases are almost equal; in case of zero normal contributions, costs are even slightly lower when holding all equities compared to the pure bond portfolio.

This might seem counter-intuitive, but it is attributable to the spread method used to amortize any over- or underfunding. In case of negative capital market shocks, a funding shortfall is not recovered by immediate supplementary contributions but rather is filled with small additional annual contributions. ${ }^{20}$ This leaves open the possibility that the gap could be at least partially closed by subsequent positive developments in the capital markets. In the event of positive capital market shocks, on the other hand, excess funds are not immediately withdrawn in full. Substantial amounts remain in the plan for longer periods of time, creating a buffer stock for possibly weak future investment performance. Moreover, these funds continue to be invested in the plan portfolio offering a chance of better returns in a strong market. This argument holds particularly true in the event of low regular normal contribution rates. Here, cashing in equity premiums is of the essence when trying to reduce expensive supplementary contributions and thereby overall pension costs. ${ }^{21}$

The positive effects of gradually amortizing funding deviations are influential when a fund holds either pure equity or pure bonds in the portfolio. Nevertheless, the impact is stronger when the fund holds all equity, than all bonds. If all over- or underfunding were fully recovered in the next period (i.e. the spread period were set to 1), worst-case pension costs

\footnotetext{
${ }^{20}$ This of course assumes that the plan sponsor is able and willing to sustain longer periods of the pension plan being underfunded. As in this study the government is the plan sponsor, we take this for granted (especially since the current system is a completely underfunded pay-as-you-go system).

${ }^{21}$ This is in line with Josa-Fombellida and Rincón-Zapatero (2006), who find that increasing funding deficits trigger higher risk-taking. A case in point is the underfunded US Pension Benefit Guaranty Corporation which recently announced it would move away from a mostly bond portfolio toward a 55 percent allocation in equities and non-traditional assets. This was justified as providing "a 57 percent likelihood of full funding within ten years, compared to 19 percent under the previous policy." See PBGC (2008).
} 
for normal contributions of 0 (40) percent would amount to $€ 69.12(70.77)$ billion in case of a pure equity strategy, and $€ 37.95$ (37.25) billion when fully investing in bonds.

Summarizing the results for the base case with a spread period of 20 years, we conclude that the manager seeking to control worst-case overall pension costs will select a normal contribution rate of about 20 percent and equity weights of about 40 percent.

Next we direct our attention to contribution rate risk. Figure 2 depicts the average annual contribution rate volatility, or the deviation of actual from normal contributions as a percent of salary payments for different contribution rates and asset allocations. For a normal contribution rate of 0 percent and a portfolio entirely invested in bonds, the annual contribution rate volatility is 2.88 percent which falls quickly as contributions rise to around 14 percent of the payroll. A further increase in regular payments again results in rising contribution rate volatilities which reach an annual value of 3.78 percent for a normal contribution rate of 40 percent. This pattern is intuitive since our earlier results showed that minimum volatility (in this case constant) regular contributions of 18.7 percent of the payroll are sufficient to fund the pension in a deterministic set-up without capital market risk. Engaging in risky investment strategies reduces the minimum volatility normal contribution rate sufficient to fund the plan, at the price of some positive contribution rate volatility related to capital market risks (instead of zero volatility as in the deterministic case). Lower normal contributions will constantly require the triggering of supplementary contributions which boosts contribution rate volatility. In turn, choosing too high a normal contribution rate leads to continuous reductions in actual contributions due to amortization of asset surpluses, which also increases contribution rate volatility.

Figure 2 here

The impact of adding equities to the pension plan's portfolio depends on the plan's funding situation. For low normal contribution rates which result in the plan being chroni- 
cally underfunded, contribution rate volatility decreases with increasing equity weights. In case of a 0 normal contribution rate, volatility drops from 2.88 percent when the plan holds only bonds, to 2.20 percent when the entire portfolio is held in equities. If normal contribution rates are high enough to fund or even overfund the plan, contribution rate volatility rises with increasing equity exposure. For normal contributions of 40 percent, contribution rate volatility will rise from 3.78 percent (pure bond investment) to 4.5 percent for all equities portfolios, a rather moderate increase.

This behavior is again driven by the amortizing of over- or underfunding, as spreading the inflows can substantially reduce the impact of capital market volatility. If normal contributions are low, contribution rate volatility mainly results from continuously required supplementary contributions. Investing a substantial part of the plan assets in equities may offer the chance to cash-in on higher equity premiums and thereby reduce the need for expensive supplementary contributions. Yet this comes at the cost of increased capital market risk. Due to the smoothing effects of the spread method applied and the generally poor funding situation, these capital market fluctuations have only minor negative impacts on the contribution rate volatility. These are more than compensated by contribution rate volatility reducing effects of earning higher investment returns on average.

If, in turn, the plan is sufficiently funded or even substantially overfunded, there is no need for earning excess investment returns. On the contrary, both effects discussed above will increase contribution rate volatility. Higher expected equity premiums will further improve the funding situation and therefore lead to even lower actual contribution rates and increased contribution rate volatility. In addition, possible adverse capital market shocks in combination with high levels of plan assets will cause substantial capital losses, again resulting in increasing contribution rate volatility. For the reasons discussed above, however, the absolute negative impact of increased capital market risk on contribution rate volatility is moderate. 
If all over- or underfunding were fully recovered in a single period (i.e. the spread period were set to 1), contribution rate volatility would rise for all combinations of normal contributions and investment strategies, especially for asset allocations with high equity exposure. For normal contributions of 0 (40) percent, contribution rate volatility would come in at 6.06 (4.78) percent when fully investing in bonds, and more than twice this -- 14.59 (12.66) percent - in the case of a pure equity strategy. This shows that the smoothing effects of the spread method applied are particularly beneficial in the case of low normal contributions.

Summarizing, for the base case with a spread period of 20 years, contribution rate volatility is lowest for normal contribution rates of about 14 percent and equity weights of 0 percent.

\subsection{Deriving the Optimal Contribution Rate and Asset Allocation}

The discussion of worst-case pension costs and contribution rate volatility patterns in the previous section suggests ambiguous results with respect to the optimal combination of normal contribution rate and asset allocation. Minimizing the Conditional Value at Risk of overall pension costs at the 1 percent level would require contributing at a normal rate of about 20 percent and investing about 40 percent of plan assets in equities. By contrast, focusing on the volatility of the (actual) contribution rate requires normal contributions of about 14 percent and a pure bond investment allocation. Accordingly, we next derive the optimal contribution and investment strategy, so as to minimize the volatility of contributions while at the same time controlling for worst-case pension costs.

The optimal combination of normal contribution rates and equity weights appears in Figure 3. Two sets of indifference curves appear in the equity weight/normal contribution rate plane. The first set of U-shaped curves, which open toward the top of the Figure, represent combinations of normal contribution rates and equity weights that result in equal worst-case pension costs. The $1 \%-\mathrm{CVaR}$ of costs not to be exceeded is set to $€ 20.8$ billion, which re- 
sembles the deterministic pension costs established in section 2.3 (black solid line). Contribution rate/equity weight combinations inside this curve result in lower worst-case pension costs, those outside cause higher costs as indicated by the two additional indifference curves (grey solid lines).

Figure 3 here

Next, we seek to identify the one (feasible) normal contribution rate/equity weight strategy that will minimize contribution rate volatility subject to lying on or inside the black solid indifference curve representing the worst-case costs (of $€ 20.8$ billion). To this end, Figure 3 shows a second set of U-shaped indifference curves, opening to the left of the Figure, which represent combinations of normal contribution rates and equity weights resulting in equal contribution rate volatilities. The black solid line combines all strategies that lead to an average annual contribution rate volatility of 1.25 percent. Combinations inside this curve exhibit lower, those outside higher contribution rate risk.

The optimal combination of the normal contribution rate and the equity weight can then be determined by the point at which both black solid indifference curves are tangent to each other. No other funding/investment combination with worst-case costs restricted to a maximum of $€ 20.8$ billion has lower contribution rate risk. For our base case (spread period 20 years), this optimal combination consists of contributing to the plan at a normal rate of 13.4 percent and investing plan assets in a constant-mix allocation with 40.9 percent equities and 59.1 percent bonds.

Worst-case costs are well-controlled in this setup, but the potential benefits of this strategy, besides relatively stable contribution rates, become obvious when looking at expected overall pension costs. These are computed at only $€ 3.2$ billion, substantially below plan costs in the deterministic case (i.e. $€ 20.8$ billion). The reduction in costs may be attributed to better funding combined with a well-diversified investment strategy. With an ex- 
pected annual portfolio return of 5.1 percent, investment income on plan assets regularly exceeds the discount rate of liabilities. While the single-period portfolio volatility of 11.1 percent cannot be neglected, mean reversion characteristics in the equity returns as well as the spread method applied keep capital market risks at a tolerable level. In this environment, excess funds are regularly built up so actual contribution rates can be reduced, and remaining excess funds can be withdrawn, all of which will reduce overall pension costs.

Table 2 summarizes optimal contribution and investment patterns for various spread periods. Normal contribution rates (Row 1), equity and bond weights (Rows 2-3), the average annual contribution rate volatility (Row 4), as well as worst-case and expected pension costs (Rows 5-6) are presented for a short-term spread period of 1 year (Column 1), for mediumterm spread periods of 10 years and our base case (spread period 20 years) (Column 2-3), as well as for long-term spread periods of 50 and infinite years (Columns 4-5).

Table 2 here

Due to our restriction on worst-case costs, optimal strategies for all spread periods exhibit a 1\%-CVaR of pension costs of $€ 20.8$ billion (Row 5). From Row 4 it can be seen that contribution rate volatility declines monotonically for increasing spread periods, ranging from 3.24 percent p.a. in the case of a 1-year spread period (Column 1) to 1.09 percent when funding deviations are spread over an infinite horizon (Column 5). Contribution rate volatility mainly results from capital market volatility leading to fluctuations in the plan's funding situation. Spreading funding deviations over longer horizons reduces the impact of short-term capital market fluctuations on required contributions in any single period.

Apart from contribution rate volatility, one must use caution when comparing any of the other parameters included in Table 2 across different spread periods. Looking at Row 1, one might find it striking that optimal normal contributions first drop and later increase again with increasing spread periods. One might surmise that there is some optimal spread period 
between 1-10 years that will minimize normal contributions. The fallacy of this argument is that we do not minimize normal contributions but rather look at the volatility of overall contributions. This argument also holds when comparing the other parameters. What can be seen, however, is that, apart from very short spread periods, contribution and investment strategies that minimize contribution rate volatility are rather stable, no matter how long the chosen spread period. If deviations are spread over 10 years (Column 2), the optimal strategy would require to set normal contributions at 13 percent (Row 1) and invest about 42 (58) percent of plan funds in equities (bonds; Rows $2 \& 3$ ). The extreme case of spreading funding surpluses or shortfalls over an infinite horizon (Column 5) would call for normal contributions of 14 percent (Row 1), or only 1 percent more than in the former case. Optimal equity exposure would drop by less than 3 percent to about 39.5 percent (Column 5, Row 2). Contribution rate volatility (Row 4) exhibits the same characteristics, dropping only marginally from 1.38 in case of 10 years (Column 2) to 1.09 percent for an indefinite horizon (Column 5).

\subsection{Development of Contribution Rates over Time}

We next turn our attention to the time path of contribution rates under the optimal (normal) contribution and investment strategy. While the rate of normal contributions is fixed, overall contributions in each period may deviate from the normal rate depending on the funding situation of the pension plan.

Figure 4 depicts the expected value as well as the 95\%-quantile (worst-case quantile) of overall contributions for our base case with a spread period of 20 years and penalty factors of 20 percent. From above, recall that the optimal fixed normal contribution rate in this case is 13.4 percent with about 41 percent of plan funds being invested in equities (Table 2, Column 3, Rows 1 \& 2). Looking at the expected overall contribution rate represented by the solid line in Figure 4, in early years the fixed normal contribution rate is insufficient to fund accruing pension benefits. Starting from the normal contribution rate of 13.4 percent in year 
1, actual contributions rise continuously to attain a maximum of 15.19 percent in year 9 . From this point onward, overall contributions decline. With 13.09 percent, the contribution rate drops below the fixed normal rate in year 18 for the first time and continues to fall to about 1.4 percent toward the end of our projection.

In the early years, the size of the funds accumulated in the plan is relatively low compared to salary payments and accruing pension benefits; for instance we above computed that deterministic contribution rate of 18.7 percent is required to fund pension benefits using the base discount rate of 3 percent. Initial contributions fall short of that by over 5 percentage points (almost 30 percent). Earning an expected return of about 5 percent on the small absolute amount of plan assets does not suffice to cover that shortfall, so overall contributions must be boosted due to the expected funding shortfall. Nevertheless, they rise slowly since the immediate impact of the deficit on contributions is cushioned by the spread approach. As the magnitude of fund assets rises, the approximately 2 percent excess return over the discount rate earned by investing in risky equities and bonds should cover the difference between accruing pension benefits and contributions to fund them. In turn, overall expected contributions fall in later periods as the pension plan holds substantial assets.

\section{Figure 4 here}

Turing our attention to the $95 \%$-quantile of overall contributions, represented by the dashed line in Figure 4, we identify a comparable pattern. If capital markets underperform, contributions rise to a higher level of about 21.8 percent in year 20. The decline in later years is also substantially smaller than in expectation, with overall contributions falling short of the normal contribution rate only from year 47 onwards and reaching a minimum of 11.6 percent toward the end of our projection. The fact that contribution rates in later periods drop can be attributed to mean reversion inherent in asset returns resulting in a considerable reduction of return volatility over the long run. 
Table 3 summarizes expected and 95\%-quantile overall contribution rates for all spread periods under investigation and for selected time points. In line with our earlier results, we find that the amplitude of contribution rate variation over time decreases with longer spread periods. As one would anticipate, this is particularly important for the $95 \%$-quantile of overall contributions.

\section{Table 3 here}

Looking at expected contribution rates for a one year spread period (Table 3, Row 1), it can be seen that these rates continuously decline over time. Starting at 23 percent in year 1 (Column 1), they drop to only 0.9 percent in the last year (Column 6). In this case, the initial contribution rate is above the one required in the deterministic case, which immediately leads to a reduction in contribution rates. The pension plan is well-endowed from the beginning and expected excess returns on the assets help to reduce expected overall contributions. The downside of missing the opportunity to smooth contributions over time becomes apparent when looking at the $95 \%$-quantile of contributions. These may rise to a maximum of about 60 percent around year 20 (Row 6, Column 3). Over very long horizons, however, the reduction of long-term asset volatility kicks in again and even in 95 percent of paths no additional contributions are required (Row 6, Column 6).

For spread periods from 10 years to infinity, there are only minor differences in the optimal contribution and investment strategy. It is therefore not surprising that contribution rate patterns over time for all other spread periods come very close to the base case discussed above.

\subsection{Further Results}

Thus far, all analyses have used the base case with a real discount rate of 3 percent, standard expectations for equities and bonds, and penalty factors on supplementary contribu- 
tions and withdrawals of $\xi_{1}=\xi_{2}=0.2$. Next we vary these assumptions to explore robustness.

In the early 2000 s, many pension plans faced severe financial distress due to the capital market downturn which left plan assets crumbling just when low interest rates boosted pension liabilities. Accordingly we next analyze how our pension plan would behave in such a 'perfect storm' environment. To this end, we assume that the discount rates as well as expected returns on equities and bonds fall to 1.5 percent, and expected asset returns behave according to the low return scenario in Table 1.

It may be recalled that under this lower discount rate, the deterministic PBO totals $€$ 44.8 billion. Letting this be the restriction on worst-case costs and keeping the penalty factors at $\xi_{1}=\xi_{2}=0.2$, neither combination of normal contributions and investment strategies will be able to comply with this limit at the $1 \%$-CVaR level, for any spread period. For a spread period of 20 years, the $1 \%$-CVaR finds its minimum at $€ 46.5$ billion for normal contributions of 20 percent and an equity weight of 41 percent. In fact, the $1 \%$-CVaR restriction can only be met by relaxing the penalty factors for funding deviations. For instance, if $\xi_{1}=\xi_{2}=0$, there are viable solutions for all spread periods under investigation. Given a spread period of 1 year, the optimal normal contribution rate would be 16.1 percent and 23 percent of fund assets would be held in equities; this results in contribution rate volatility of 3.73 percent p.a. Contribution rate volatilities for other spread periods are substantially lower, ranging from 1.62 percent p.a. in case of 10 years, to 0.54 percent p.a. in case of an infinite spread period. Nevertheless, optimal contribution and investment strategies change little. Volatilityminimizing contribution rates in these cases vary between 15.1 and 15.5 percent, while optimal equity weights lie between 27 and 29 percent. Spreading funding deviations over longer time leads to increased tolerance for capital market volatility and therefore rising appetite for 
equities. As expected return on equities still exceeds that of bonds, there is some room for reducing contribution rates but it is small.

Conversely, if penalty factors are maintained for incentive reasons, the only way to generate feasible solutions requires relaxing the overall worst-case cost risk tolerance. For instance, setting the $\mathrm{CVaR}$ at 5 percent, and assuming $\xi_{1}=\xi_{2}=0.2$ as in the base case, results in solutions comparable to those reported previously. Optimal contribution rate volatilities are virtually unchanged. Imposing penalties on funding deviations, however, leads to marginally higher contribution rates, varying between 16 and 17 percent for different spread periods, and slightly reduced equity exposure, with equity weights ranging between 21 and 25 percent. Expected overall pension costs would come to $€ 23.88$ billion, down by almost 50 percent with respect to the deterministic pension liability.

Next we turn our attention to an analysis of the impact of penalizing funding deviations with extra loadings. For the base scenario discount factor of 3 percent, standard expectations on asset returns, a spread period of 20 years and $\xi_{1}=\xi_{2}=0.2$, we learned that the optimal strategy includes a normal contribution rate of 13.4 percent and an equity fraction of 40.9 percent, resulting in contribution rate volatility of 1.25 percent p.a. Cutting penalties relaxes the restriction on worst-case costs and more combinations of normal contribution rate and asset allocation become available to the plan manager. For penalty factors of $\xi_{1}=\xi_{2}=0$, contribution rate volatility can be reduced to 0.93 percent $\mathrm{p}$.a. by only contributing at a normal rate of 11.2 percent and financing possible shortfalls from costless supplementary contributions. In order to meet the cost restriction, some equity investments totaling 10 percent are still required to exploit excess returns. Otherwise, contribution volatility might be reduced even further. 


\section{Conclusions}

Most public pensions in the developed world are unfunded, noncontributory, and taxsponsored defined benefit plans. These represent a substantial, and at present, mostly unrecognized liability to taxpayers, one which threatens to grow as the workforce ages. Against this backdrop, we evaluate ways to fund newly accrued pension benefits for the civil service pension of the German state of Hesse, allowing the plan manager to invest fund assets in the capital market, using strategic contribution and investment patterns that minimize contribution rate volatility while controlling for overall pension costs with respect to a CVaR cost constraint. We show that controlling only for costs results in high regular contribution rates, of about 40 percent of covered payroll. Controlling only on contribution rate volatility yields more moderate contribution rates and low-risk asset allocations, but high supplementary transfers to fill shortfalls. Combining both approaches results in moderate contribution rates paired with substantial equity holdings.

This research should be of interest to policymakers across Europe and the Americas, inasmuch as many of their public sector plans face substantial funding shortfalls. Plan managers should also be interested, as we have proved under plausible assumptions that they can identify and implement a sensible balancing act between investment in equities and contribution policies, while protecting taxpayers from undue risk. A key message is that investing in pure bond portfolios, which represents the status quo investment policy for the handful of currently partially-funded German pension schemes, may not be the best way to exploit capital markets. Yet investing public pension money 60 percent or more in equities, as is true for many US state pension plans, will prove too aggressive when future taxpayer consequences are properly accounted. 


\section{References}

ABP, 2006. ABP Annual Report 2006. Heerlen: ABP Investments.

Artzner, P., Delbaen, F., Eber, J., Heath, D., 1997. Thinking Coherently. Risk 10 (11), 68 72.

Artzner, P., Delbaen, F., Eber, J., Heath, D., 1999. Coherent Measures of Risk. Mathematical Finance 9 (3), $203-228$.

Blake, D, 2006. Pension Finance. Chichester: Wiley.

Bogentoft, E., Romeijn, H.E., Uryasev, S., 2001. Asset/Liability Management for Pension Funds Using CVaR Constraints. Journal of Risk Finance 2 (3), 57-71.

Brandt, M.W., Santa-Clara, P., 2006. Dynamic Portfolio Selection by Augmenting the Asset Space. Journal of Finance 61 (5), 2187-2217.

Bundesministerium des Innern, 2005. Dritter Versorgungsbericht der Bundesregierung. Berlin.

Campbell, J.Y., Chan, Y.L., and Viceira, L.M., 2003. A Multivariate Model for Strategic Asset Allocation. Journal of Financial Economics 67, 41-80.

Campbell, J.Y., and Shiller, R.J., 1988. Stock Prices, Earnings and Expected Dividends. Journal of Finance 43, 661-676.

Campbell, J.Y., and Shiller, R.J., 1991. Yield Spreads and Interest Rate Movements: A Bird's Eye View. Review of Economic Studies 58, 495-514.

Campbell, J.Y., and Viceira, L.M., 2005. The Term Structure of the Risk-Return-Trade-Off. Financial Analysts Journal 61, 34-44.

Campbell, J.Y., and Viceira, L.M., 2002. Strategic Asset Allocation: Portfolio Choice for Long-Term Investors. Oxford: Oxford University Press.

Chang, S.C., Tzeng, L.Y., Miao, J.C., 2003. Pension Funding Incorporating Downside Risks. Insurance: Mathematics and Economics, 32, 217-228.

Cochrane, J.H., 2005. Asset Pricing. Princeton: Princeton University Press.

Detemple, J., Rindisbacher, M., 2008. Dynamic Asset Liability Management with Tolerance for Limited Shortfalls. Insurance: Mathematics and Economics, doi:10.1016/j.insmatheco.2008.05.009.

DAV - Deutsche Aktuarsvereinigung, 2004. Herleitung der DAV-Sterbetafel 2004 R für Rentenversicherungen. Köln.

Dufresne, D., 1988. Moments of Pension Contributions and Fund Levels when Rates of Return are Random. Journal of the Institute of Actuaries 115, 535-544. 
Fama, E.F., and French, K.R., 1989. Business Conditions and the Expected Returns on Stocks and Bonds. Journal of Financial Economics 25, 23-49.

Feldstein, M., and Ranguelova, E., 2001. Individual Risk in an Investment-Based Social Security System. NBER Working Paper 8074.

Haberman, S., 1997a. Stochastic Investment Returns and Contribution Rate Risk in a Defined Benefit Pension Scheme. Insurance: Mathematics and Economics 19, 127 - 139.

Haberman, S., 1997b. Risk in a Defined Benefit Pension Scheme. Singapore International Insurance and Actuarial Journal 1, 93-103.

Haberman, S., Butt, Z., and Megaloudi, Ch., 2000. Contribution and Solvency Risk in a Defined Benefit Pension Scheme. Insurance: Mathematics and Economics 27, 237-259.

Haberman, S., Day, C., Fogarty, D., Khorasanee, M.Z., McWhirter, M., Nash, N., Ngwira, B., Wright, I.D., and Yakoubov, Y., 2003a. 'A Stochastic Approach to Risk Management and Decision Making in Defined Benefit Pension Schemes.' British Actuarial Journal 9 (3), 493-618.

Haberman, S., Khorasanee, M.Z., Ngwira, B., and Wright, I.D., 2003b. Risk Measurement and Management of Defined Benefit Pension Schemes: A Stochastic Approach. IMA Journal of Management Mathematics 14, 111-128.

Haberman S., and Sung, J.H., 1994. Dynamic Approaches to Pension Funding. Insurance: Mathematics and Economics 15, 151-162.

Haberman S., and Sung, J.H., 2005. Optimal Pension Funding Dynamics over Infinite Control Horizon when Stochastic Rates of Return are Stationary. Insurance: Mathematics and Economics 36, 103-116.

Hainaut, D., and Devolder, P., 2007. Management of a Pension Fund under Mortality and Financial Risks. Insurance: Mathematics and Economics 41, 134-155.

Heubeck, K., and Rürup, B., 2000. Finanzierung der Altersversorgung des öffentlichen Dienstes. Frankfurt: Peter Lang Verlag.

Hoevenaars, R.P., Molenaar, R.D., Schotman, P.C., and Steenkamp, T.B., 2008. Strategic Asset Allocation with Liabilities: Beyond Stocks and Bonds. Journal of Economic Dynamics and Control, doi:10.1016/j.jedc.2007.11.003.

Hoevenaars, R.P., Molenaar, R.D., and Steenkamp, T.B., 2003. Simulation for the Long Run. In: Scherer B. (Ed.). Asset Liability Management Tools. London: Risk Books, 177210 .

Hustead, E.C., and Mitchell, O.S., 2001. Public Sector Pension Plans. In: Mitchell, O.S., Hustead, E.C. (Eds.). Pensions in the Public Sector. Philadelphia: University of Pennsylvania Press, $3-10$. 
Josa-Fombellida, R., and Rincón-Zapatero, J.P., 2006. Optimal Investment Decisions with a Liability: The Case of Defined Benefit Pension Plans. Insurance: Mathematics and Economics 39, 81-98.

Lee, E.M., 1986. An Introduction to Pension Schemes. Institute and Faculty of Actuaries, London, UK.

Maurer, R., Mitchell, O.S., and Rogalla, R., 2008a. The Victory of Hope over Angst? Funding, Asset Allocation, and Risk Taking in German Public Sector Pension Reform. In: Broeders, D., Eijffinger, S., Houben, A. (Eds.). Frontiers in Pension Finance. Cheltenham: Edward Elgar, 51-79.

Maurer, R., Mitchell, O.S., and Rogalla, R., 2008b. Reforming German Civil Servant Pensions: Funding Policy, Investment Strategy, and Intertemporal Risk Budgeting. PRC Working Paper, 2008-09.

McGill, D.M., Brown, K.N., Haley, J.J., and Schieber, S.J., 2005. Fundamentals of Private Pensions. 9th Ed. Oxford: Oxford University Press.

Mitchell, O.S., McCarthy, D., Wisniewski, S.C., and Zorn, P., 2001. Developments in State and Local Pension Plans. In: Mitchell, O.S., Hustead, E.C. (Eds.). Pensions in the Public Sector, Philadelphia: University of Pennsylvania Press, $11-40$.

Ngwira, B., and Gerrard, R., 2007. Stochastic Pension Fund Control in the Presence of Poisson Jumps. Insurance: Mathematics and Economics 40, 283-292.

Novy-Marx, and R., Rauh, J.D., 2008. The Intergenerational Transfer of Public Pension Promises. Working Paper, http://ssrn.com/abstract=1156477.

Owadally, M.I., and Haberman, S., 1999. Pension Fund Dynamics and Gains/Losses due to Random Rates of Investment Return. North American Actuarial Journal 3 (3), 105 117.

Owadally, M.I., and Haberman, S., 2004. Efficient Amortization of Actuarial Gains/Losses and Optimal Funding in Pension Plans. North American Actuarial Journal 8(1), 21 36.

PBGC.Pension Benefit Guaranty Corporation, 2008. PBGC Announces New Investment Policy. Washington, D.C.: PBGC. http://www.pbgc.gov/media/news-archive/newsreleases/2008/pr08-19.html Viewed 24/8/08.

Rockafellar R.T., and Uryasev, S., 2002. Conditional Value-at-Risk for General Loss Distributions. Journal of Banking and Finance 26, 1443-1471.

Winklevoss, H.E., 1993. Pension Mathematics with Numerical Illustrations. 2nd Ed. Philadelphia: University of Pennsylvania Press. 
Table 1: Simulation Model Parameters for Stochastic Asset Case

\begin{tabular}{|c|c|c|c|c|c|}
\hline & \multicolumn{2}{|c|}{ Expected Returns } & & \multicolumn{2}{|c|}{ Correlations } \\
\hline & $\begin{array}{c}\text { Base case } \\
\text { scenario }\end{array}$ & $\begin{array}{l}\text { Low return } \\
\text { scenario }\end{array}$ & $\begin{array}{c}\text { Standard } \\
\text { deviations }\end{array}$ & Equities & Bonds \\
\hline $\begin{array}{l}\text { Equities } \\
\text { Bonds }\end{array}$ & $\begin{array}{l}6.57 \% \\
4.08 \% \\
\end{array}$ & $\begin{array}{l}5.07 \% \\
2.58 \%\end{array}$ & $\begin{array}{l}23.4 \% \\
7.02 \% \\
\end{array}$ & $\begin{array}{c}1 \\
0.17\end{array}$ & 1 \\
\hline
\end{tabular}

Source: Authors' calculations.

Table 2: Influence of Spread Period on Optimal Contribution and Investment Patterns

(1) Normal contributions (in \%)

(2) Equity weight (in \%)

(3) Bond weight (in \%)

(4) Contribution rate volatility p.a. (in \%)

(5) $1 \%-C V a R$ pension costs (in $€$ bn)

(6) Expected pension costs (in $€$ bn)

\begin{tabular}{ccccc}
\multicolumn{5}{c}{ Spread period m (in years) } \\
\hline 1 & 10 & 20 & 50 & $\infty$ \\
$(1)$ & $(2)$ & $(3)$ & $(4)$ & $(5)$ \\
\hline 23.0 & 13.0 & 13.4 & 13.9 & 14.1 \\
45.0 & 42.2 & 40.9 & 39.9 & 39.4 \\
55.0 & 57.8 & 59.1 & 60.1 & 60.6 \\
& & & & \\
3.24 & 1.38 & 1.25 & 1.14 & 1.09 \\
& & & & \\
20.80 & 20.80 & 20.80 & 20.80 & 20.80 \\
-0.62 & 2.74 & 3.20 & 3.29 & 3.31
\end{tabular}

Notes: Optimal contribution and investment patterns for various spread periods. Penalty factors on funding deviations $\xi_{1}=\xi_{2}=0.2$; High return scenario. Source: Authors' calculations.

Table 3: Contribution Rates for Selected Years

\begin{tabular}{|c|c|c|c|c|c|c|c|}
\hline & $\begin{array}{l}\text { Spread } \\
\text { Period }\end{array}$ & $\begin{array}{c}\text { Year } \\
1 \\
(1) \\
\end{array}$ & $\begin{array}{c}\text { Year } \\
10 \\
(2) \\
\end{array}$ & $\begin{array}{c}\text { Year } \\
20 \\
(3) \\
\end{array}$ & $\begin{array}{c}\text { Year } \\
30 \\
(4)\end{array}$ & $\begin{array}{c}\text { Year } \\
40 \\
(5)\end{array}$ & $\begin{array}{c}\text { Year } \\
50 \\
(6) \\
\end{array}$ \\
\hline \multicolumn{8}{|c|}{ Panel 1: Expected Contribution Rates (in \%) } \\
\hline (1) & 1 & 23.0 & 14.5 & 9.3 & 4.0 & 1.6 & 0.9 \\
\hline (2) & 10 & 13.0 & 15.6 & 10.8 & 5.0 & 2.3 & 1.2 \\
\hline (3) & 20 & 13.4 & 15.2 & 12.0 & 6.0 & 2.7 & 1.4 \\
\hline (4) & 50 & 13.9 & 14.9 & 13.0 & 7.5 & 3.5 & 1.7 \\
\hline (5) & $\infty$ & 14.1 & 14.9 & 13.4 & 8.4 & 4.1 & 1.9 \\
\hline \multicolumn{8}{|c|}{ Panel 2: 95\%-Quantile Contribution Rates (in \%) } \\
\hline (6) & 1 & 23.0 & 47.1 & 59.7 & 29.5 & 0.0 & 0.0 \\
\hline (7) & 10 & 13.0 & 20.7 & 25.6 & 22.9 & 17.7 & 9.8 \\
\hline (8) & 20 & 13.4 & 18.2 & 21.8 & 20.1 & 16.5 & 11.6 \\
\hline (9) & 50 & 13.9 & 16.7 & 19.2 & 18.4 & 15.7 & 12.4 \\
\hline$(10)$ & $\infty$ & 14.1 & 16.3 & 18.2 & 17.7 & 15.5 & 12.7 \\
\hline
\end{tabular}

Notes: Expected and worst-case overall contribution rates in percent of payroll in respective period in various years for various spread periods. Penalty factors on funding deviations $\xi_{1}=\xi_{2}=0.2$; High return scenario. Source: Authors' calculations. 
Appendix: Quarterly VAR Parameters

\begin{tabular}{|c|c|c|c|c|c|c|}
\hline & $r_{m, t}$ & $x_{e, t}$ & $x_{b, t}$ & $d p_{t}$ & $\mathrm{spr}_{\mathrm{t}}$ & $r_{\text {nom,t }}$ \\
\hline \multicolumn{7}{|c|}{ Parameter estimates } \\
\hline$r_{m, t+1}$ & -0.0338 & 0.0035 & -0.0226 & -0.2118 & -0.0350 & 0.5455 \\
\hline$x_{e, t+1}$ & 0.1267 & 0.0116 & 0.0920 & 1.9727 & 0.5572 & -2.8218 \\
\hline$x_{b, t+1}$ & -0.1710 & -0.0176 & 0.1106 & -0.3946 & 0.9146 & 1.5958 \\
\hline $\mathrm{dp}_{\mathrm{t+1}}$ & -0.0099 & 0.0012 & -0.0094 & 0.9274 & -0.0169 & 0.0464 \\
\hline $\mathrm{spr}_{\mathrm{t}+1}$ & 0.0467 & 0.0005 & 0.0458 & -0.0196 & 0.9729 & 0.3110 \\
\hline$r_{\text {nom }, t+1}$ & -0.0268 & 0.0010 & -0.0173 & 0.0434 & -0.0869 & 0.7718 \\
\hline \multicolumn{7}{|c|}{ Error correlation matrix } \\
\hline$r_{m, t}$ & 0.54 & & & & & \\
\hline$x_{e, t}$ & -0.05 & 11.55 & & & & \\
\hline$x_{b, t}$ & 0.19 & -0.07 & 3.00 & & & \\
\hline $\mathrm{dp}_{\mathrm{t}}$ & 0.06 & -0.87 & 0.12 & 0.30 & & \\
\hline $\mathrm{spr}_{\mathrm{t}}$ & 0.01 & 0.05 & -0.42 & -0.10 & 0.62 & \\
\hline 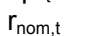 & 0.21 & -0.16 & 0.12 & 0.23 & -0.35 & 0.15 \\
\hline
\end{tabular}

Source: Authors' calculations. 
Figure 1: Worst-Case Pension Cost Outcomes: Present Value of 1\%-CVaR Costs ( $€$ bn).

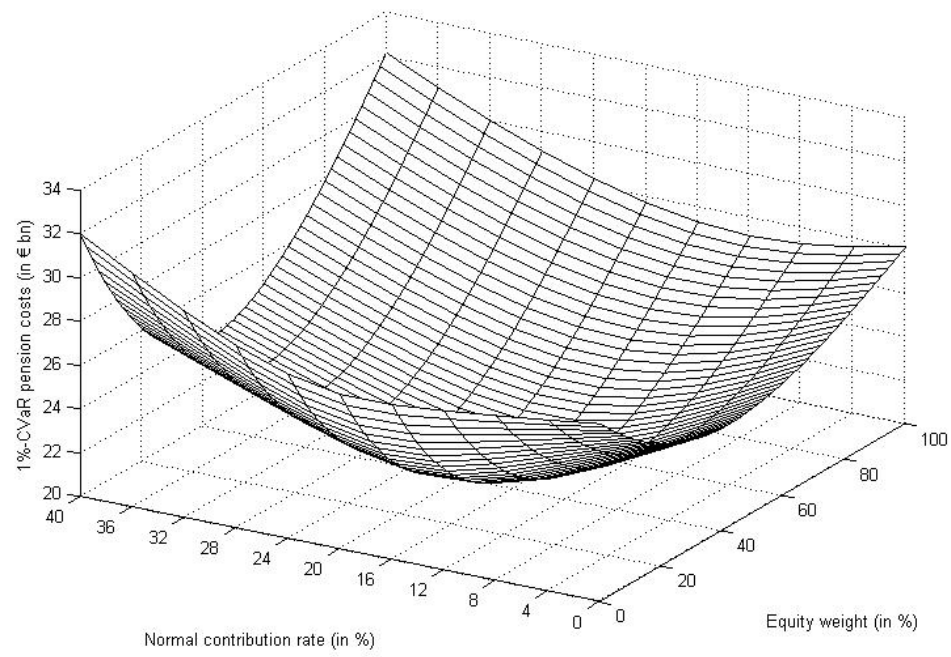

Notes: Base case assumes spread period of 20 years; a 3\% real discount rate; penalty factors on funding deviations $\xi_{1}=\xi_{2}=0.2$; high return scenario. Source: Authors' computations.

Figure 2: Pension Contribution Rate Volatility (\%)

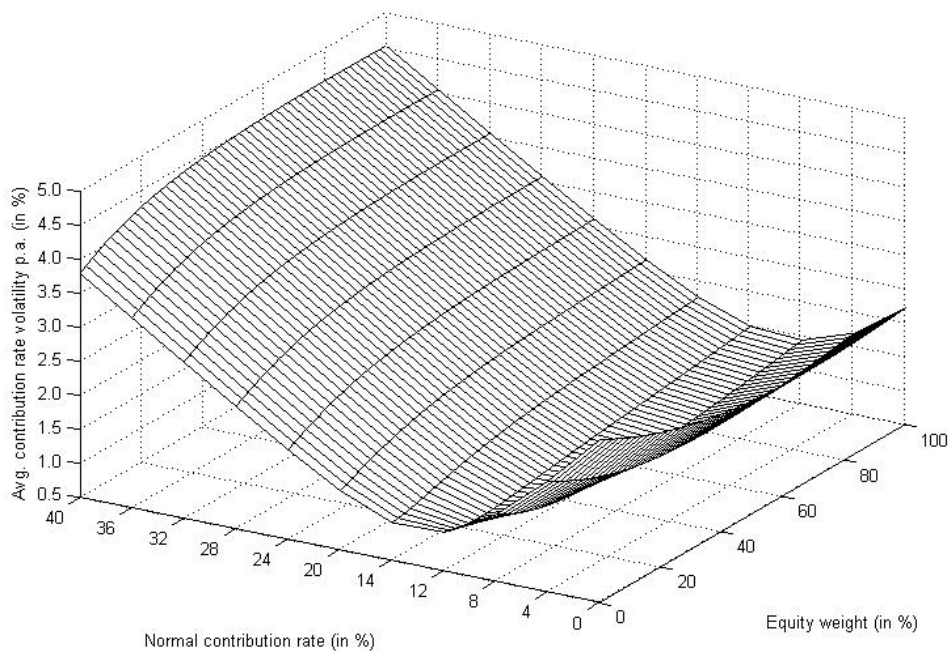

Notes: Base case assumes spread period of 20 years; a 3\% real discount rate; penalty factors on funding deviations $\xi_{1}=\xi_{2}=0.2$; high return scenario. Source: Authors' computations. 
Figure 3: Pension Manager's Optimal Contribution and Investment Strategy Indifference Map

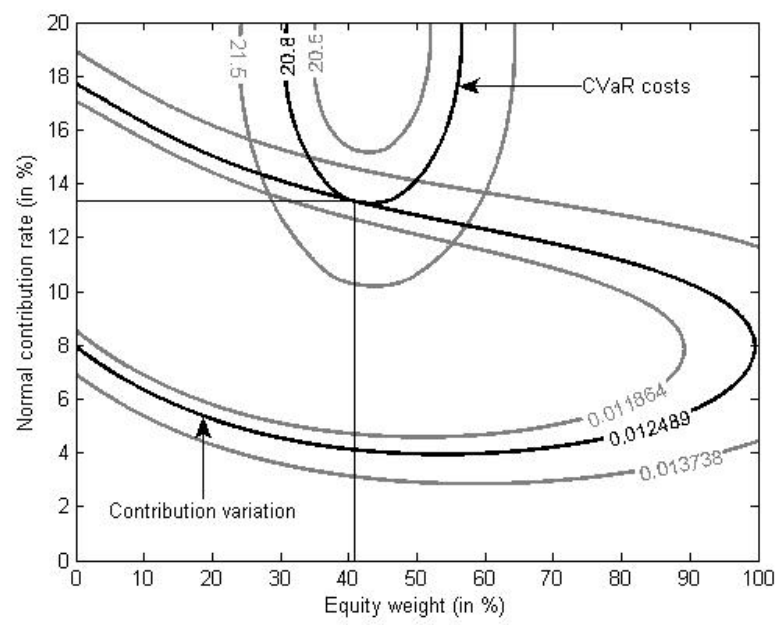

Notes: Base case assumes spread period of 20 years; a 3\% real discount rate; penalty factors on funding deviations $\xi_{1}=\xi_{2}=0.2$; high return scenario. Source: Authors' computations.

Figure 4: Total Pension Contribution Rate Profile over Time (\%)

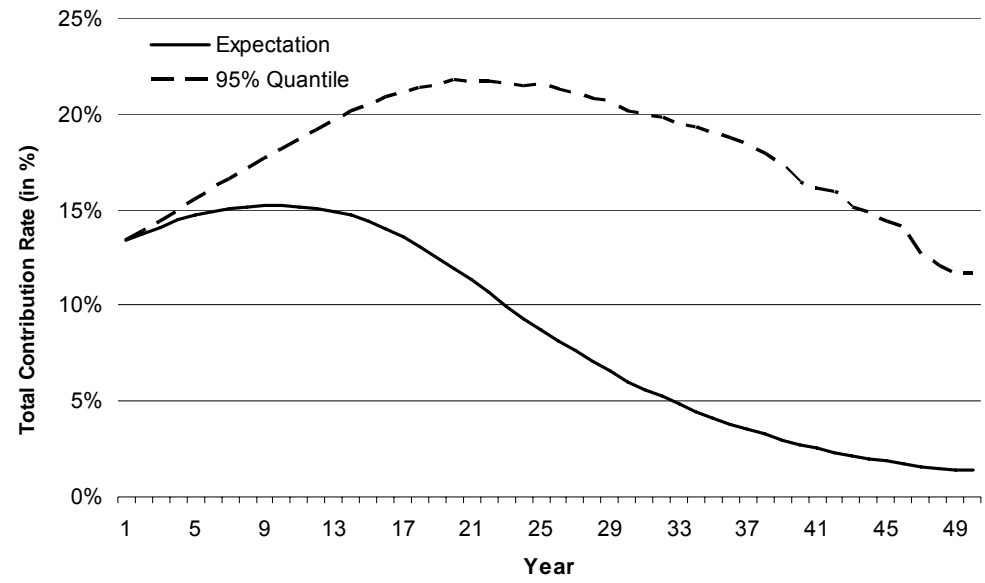

Notes: Total pension contributions as a percent of payroll by period. Base case assumes spread period of 20 years; a 3\% real discount rate; penalty factors on funding deviations $\xi_{1}=\xi_{2}=0.2$; high return scenario. Source: Authors' computations. 